\title{
Alemtuzumab: A Place in Therapy for Treatment of Multiple Sclerosis ${ }^{*}$
}

\author{
Teya M. Tietje ${ }^{1,2}$, Douglas R. Allington ${ }^{1,2}$, Michael P. Rivey ${ }^{1,2}$ \\ ${ }^{1}$ Skaggs School of Pharmacy, University of Montana, Missoula, USA; ${ }^{2}$ Pharmacy Department, Community Medical Center, Mis- \\ soula, USA. \\ Email: teya.tietje@umontana.edu
}

Received August $24^{\text {th }}, 2013$; revised September $23^{\text {rd }}, 2013$; accepted October $4^{\text {th }}, 2013$

Copyright (C) 2013 Teya M. Tietje et al. This is an open access article distributed under the Creative Commons Attribution License, which permits unrestricted use, distribution, and reproduction in any medium, provided the original work is properly cited.

\begin{abstract}
Alemtuzumab is a humanized mononclonal antibody known to cause rapid depletion of B- and T-cell lymphocytes. Subsequent repletion of these lymphocytes leads to changes in adaptive immunity. Alemtuzumab is approved by the United States Food and Drug Administration (FDA) for the treatment of B-cell lymphocytic leukemia but has been investigated off-label in recent years for treatment of autoimmune diseases, including multiple sclerosis (MS). In MS treatment, alemtuzumab is administered as pulsed therapy, given once daily initially for 5 consecutive days and then for 3 consecutive days at 12-month intervals. Alemtuzumab has recently been compared to interferon beta 1-a in one phase II and two phase III trials in patients with relapsing-remitting MS. Results from the studies show alemtuzumab compared to interferon beta 1-a is associated with a greater reduction in the risk of sustained accumulation of disability and is more effective in reducing disease relapse rates. The treatment of MS continues to be a healthcare challenge due to the modest clinical benefit and adverse effect profiles of available disease modifying treatment options. Available data suggest alemtuzumab may offer better efficacy outcomes compared to traditional disease modifying therapies in patients with MS. However, the agent has not been compared to other new disease modifying medications that have been recently introduced.
\end{abstract}

Keywords: Alemtuzumab; Multiple Sclerosis; Monoclonal Antibody; Lymphocyte Depletion

\section{Introduction}

Multiple Sclerosis (MS) is a chronic, progressive inflammatory disease affecting the central nervous system (CNS), resulting in demyelination and irreversible axonal damage of nerves in the CNS. Abnormal activation of the immune system against antigens results in disruption of the blood-brain barrier (BBB) allowing inflammatory mediators access to the CNS, leading to widespread inflammation and subsequent neurodegeneration. A result of the destruction of myelin and central neurons is nerve conduction abnormalities.

The clinical presentation of MS varies widely between patients as well as during the disease course in individual patients. Depending on the area of the brain and spinal cord damage, symptomatic disease presentation consists of a wide range of symptoms including weakness, fatigue, paresthesias, ataxia, speech dysfunction, and cognitive changes. Magnetic resonance imaging (MRI) evidence of

\footnotetext{
*The authors report no conflicts of interest in this work.
}

CNS plaques and dissemination of brain lesions is an objective sign of possible MS [1,2]. The diagnosis of MS incorporates a combination of clinical symptomatology that cannot be attributed to another disease state or illness, as well as MRI evidence. However, a symptomatic disease episode or a positive MRI scan is not independently diagnostic and must be evaluated with other evidence after consideration of differential diagnoses, thus making MS a diagnosis of exclusion.

There are several subtypes of MS classified based on clinical disease course, with the preponderance (approximately $85 \%$ ) of patients experiencing a MS disease course characterized by symptomatic episodes lasting at least twenty-four hours followed by remission, or a symptom-free period, lasting at least thirty days. This clinical disease course is referred to as relapsing-remitting multiple sclerosis (RRMS). Another MS subtype is secondary progressive (SPMS) described as accrual of disability with or without relapses; many patients with RRMS eventually develop SPMS. Other disease subtypes 
are primary progressive (PPMS), described as a slowly progressive disease that begins at disease onset without defined relapses, and progressive relapsing (PRMS) described as a progressive disease starting at onset but with relapses [1,3].

An optimal pharmacotherapeutic treatment plan has not yet been determined for MS, and there is no cure. Current MS pharmacotherapy is targeted at disease modification while incorporating acute and chronic treatment of symptoms. Disease modifying therapies (DMT) used in MS include interferon beta 1-a, immune modulators, immunosuppressants, and monoclonal antibodies [4]. Monoclonal antibodies used in the treatment of MS target specific immune molecules on the surface of cells to interfere with the inflammatory pathophysiological disease process.

\section{Epidemiology of MS}

An increase in prevalence of MS is seen above the $37^{\text {th }}$ latitude in Northern or Southern Hemisphere countries including Australia, Europe, countries of the Mediterranean, New Zealand and the United States, with the highest prevalence seen in Scotland at 145 - 193 cases per 100,000 people. Epidemiologic studies in the United States have not been extensive; however, a north-tosouth gradient is seen with MS occurring in $>50$ individuals and $\leq 30$ individuals per 100,000 people living above and below the $37^{\text {th }}$ parallel, respectively $[5,6]$. Migration studies have shown that persons who migrate from an area of high to an area of low MS prevalence have a risk intermediate to their habitation origin, whereas persons who migrate from an area of low to high MS prevalence maintain the low risk of their origin [7-9].

Several potential environmental risk factors for MS including infection, physical environment, climate, diet, and stress have been assessed for causality. Viral infections have long been an area of interest as precipitating factors of MS. Studies have evaluated an association with childhood viral infections including measles, mumps, rubella and varicella, but data have failed to demonstrate a link to MS development [10]. Epstein-Barr virus (EBV) has gained the most interest as a potential environmental factor for MS. An increased EBV antibody seroprevalence has been found to occur in MS patients compared to controls $[11,12]$. While current evidence is not sufficiently robust to confirm an increased risk of developing MS in patients with prior EBV infection, research of the association remains plausible [11,13-15]. More recently Chlamydia pneumonia and viruses such as herpes simplex and retroviruseshave drawn attention as potential candidates for increasing the risk of developing MS but conclusive data are lacking [10,16-18].

Studies evaluating exposure to sunlight and related vi- tamin D concentrations have been mostly consistent in their findings and suggest a decreased risk of MS development in subjects with high levels of sun exposure between the ages of 6 and 15 years [19]. It has been suggested that ultraviolet light may have immunosuppressive effects and increases production of vitamin D in the skin. Nevertheless, specific environmental risk factors involved in the etiology of MS remain difficult to isolate and quantify due to many other factors that contribute to the development of MS, as well as confounding factors expressed by genetically susceptible individuals [10].

Several genes are suspected to be associated with MS development including human leukocyte antigen (HLA) class I and II alleles, T-cell receptor alpha, and cytotoxic T-lymphocyte antigen 4 (CTLA4). Results of studies have shown an increased risk for first, second, and third degree relatives of MS patients when compared to the $0.1 \%$ general population risk [20]. The greatest risk is observed in an offspring of both parents with MS, with $30.5 \%$ of individuals developing the disease, compared to $2.49 \%$ in offspring of a single parent with MS [21,22]. Additionally, the disease concordance rate is near $30 \%$ in monozygotic twins compared to $4 \%$ in dizygotic twins. It is interesting that the increased risk of developing MS in the offspring of two MS positive parents is comparable to that observed in monozygotic twins, independent of parental MS status $[23,24]$.

\section{Pathophysiology of MS}

Our knowledge regarding the cellular responses and immunobiology associated with MS has benefitted substantially by tissue sample analysis obtained from MS lesions [25] and from over 70 years of animal research, primarily using experimental autoimmune encephalomyelitis (EAE) models [26]. Histologic examination of MS plaques has documented CD4+ T-lymphocytes in perivascular spaces and meninges and $\mathrm{CD} 8+\mathrm{T}$-lymphocytes in the main body of the MS lesion [27]. The specific type and number of cells differs between patients and within a given patient as the MS lesion progresses from an acute to chronic stage $[28,29]$. B-lymphocytes may act as antigen presenting cells (APC) in the CNS, similar to their known role in the peripheral immune system [30]. Oligoclonal bands of immunoglobulin $(\operatorname{IgG})$ found in the cerebral spinal fluid (CSF) of MS patients and directly from MS plaques indicate B-lymphocytes have an important role in the escalated inflammatory response.

The demyelinating plaques of MS are dependent upon the recruitment and entry of inflammatory cells into the CNS. Once activated, CD4+ and CD8+ T-lymphocytes and B-lymphocytes from the periphery cross the BBB. Cellular migration from the periphery to the CNS is assisted by integrin receptors on lymphocyte membranes 
(VLA-4) and itsup-regulatedepithelial vascular cell adhesion molecule ligand, VCAM-1 [31]. In the CNS, APCs such as dendrites, B-lymphocytes, or macrophages express major histocompatibility complexes (MHC Class I or II) thatamplify inflammatory responses directed at myelin basic protein (MBP), myelin oligodendrocyte glycoprotein (MOG), and proteolipid protein (PLP). T-cell phenotypes, primarily $\mathrm{T}_{\mathrm{H}} 1$ and $\mathrm{T}_{\mathrm{H}} 17$, produce cell line specific chemokines, cytokines, interleukins, matrix metalloproteinases (MMP), tumor necrosis factor- $\alpha$ and other inflammatory components capable of causing direct myelin injury [32]. B-lymphocyte directed antibodies assist in demyelination through several proposed pathways that include direct antibody-dependent cell-mediated cytotoxicity (ADCC), complement activation and Fc receptor stimulation of macrophages, mast cells, or natural killer cells [33] (Figure 1).

\section{Alemtuzumab}

Alemtuzumab is a CD52 surface protein specific IgG1k humanized monoclonal antibody. Alemtuzumab was originally marketed under the brand name Compath- $1 \mathrm{H}^{\circledR}$ for the treatment of B-cell chronic lymphocytic leukemia unresponsive to first-line therapy [34]. It was later evaluated for use in autoimmune diseases such as autoimmune hemolytic anemia (AIHA) and MS [35]. The remainder of this article discusses alemtuzumab and its potential role in the treatment of RRMS.

\subsection{Mechanism of Action}

Alemtuzumab exerts immunomodulatory effects in MS through prolific $\mathrm{T}$ and $\mathrm{B}$ lymphocyte depletion and subsequent repletion, resulting in long term changes in adaptive immunity [36-38]. The site of action for alemtuzumab is human CD52 antigen, a surface protein expressed on $\mathrm{T}$ and $\mathrm{B}$ lymphocytes, natural killer cells, dendritic cells and monocytes. Interestingly, the exact biological function of CD52 is unknown. During the differentiation of leukocytes, CD52 antigen is expressed on peripheral T and B lymphocytes; this occurs in both normal and

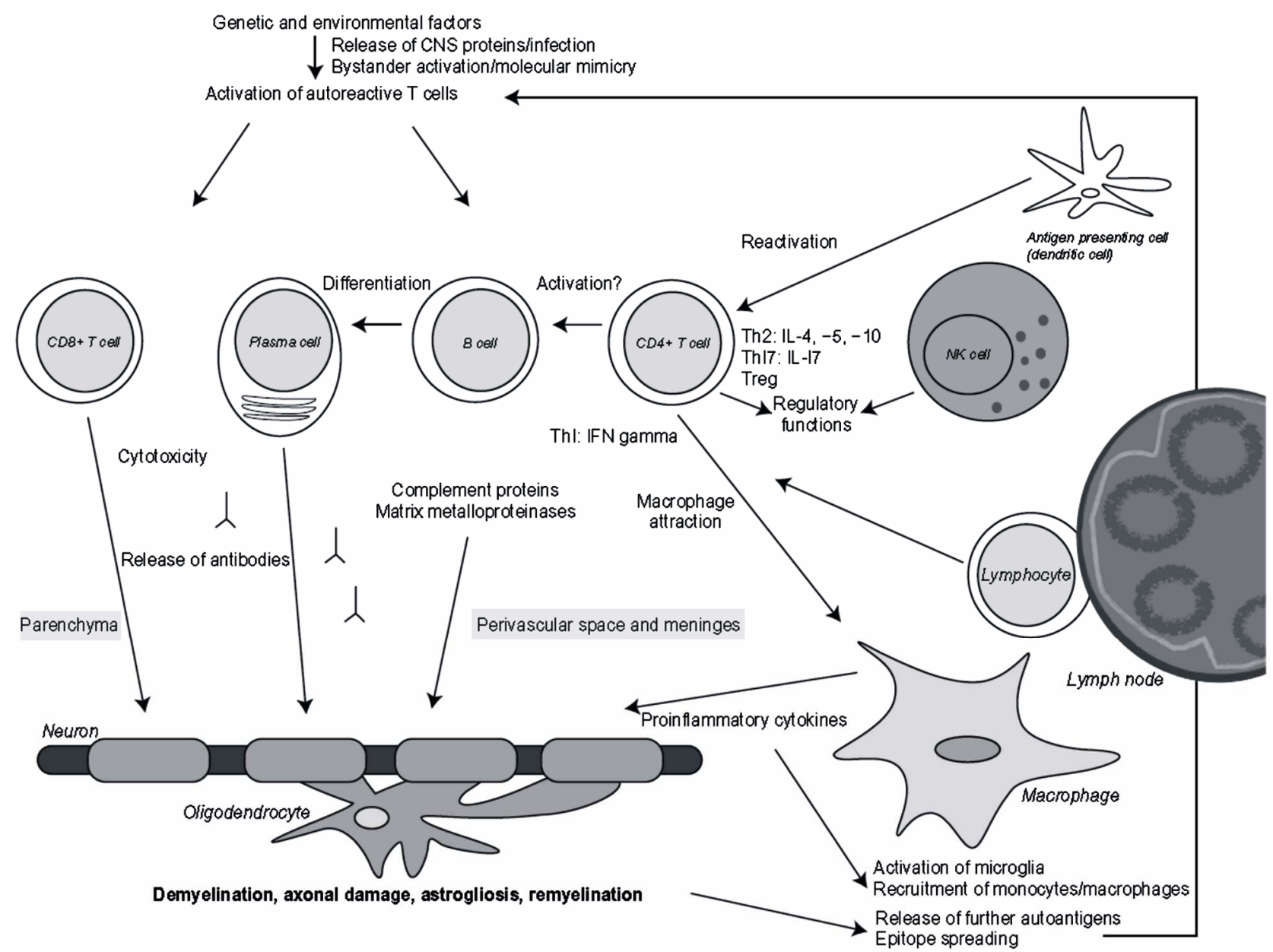

Figure 1. Immunopathogenesis of multiple sclerosis. R. C. Selter, B Hemmer, "Update on Immunopathogenesis and Immunotherapy in Multiple Sclerosis,” Immunotargets and Therapy, 2013, Vol. 2, pp. 21-30. Abbreviations: Treg, regulatory T cell; NK cell, natural killer cell; IL, interleukin. 
malignant cells, thereby explaining the development of alemtuzumab as a chemotherapeutic agent $[39,40]$. Alemtuzumab adherence to the CD52 protein induces cell lysis via complement deposition and formation of the membrane attack complex [40]. Lymphocyte lysis and depletion is proposed to promote removal of malignant lymphocytes and eliminate the involvement of normal lymphocytes in the inflammatory process.

As noted, several subtypes of $\mathrm{T}$ lymphocytes have been implicated in the release of inflammatory mediators in MS [41]. Specifically, subtype $T_{H} 1$ lymphocytes release proinflammatory cytokines associated with MS relapses, thereby providing a pharmacotherapeutic target for DMT. Moreover, there is a limited amount of CD52 antigen expressed on the surface of $\mathrm{CD} 34^{+}$hematopoietic cells, which are parent stem cells to CD52 ${ }^{+}$lymphocytes $[40,42]$. Decreased CD52 expression on the parent stem cells allows for eradication of mature lymphocytes after alemtuzumab administration without severe depletion of bone marrow cells, allowing for subsequent reconstitution of lymphocytes [40].

\subsection{Pharmacokinetics and Pharmacodynamics}

The pharmacokinetics of alemtuzumab are intertwined with the pharmacodynamics since pharmacokinetic parameters change as lymphocytes that express the CD52 antigen target of the drug are depleted [43]. Basically, the clearance of the drug is dependent on CD52 availability. This relationship contributes to large intersubject variability in alemtuzumab pharmacokinetics that is common for monoclonal antibody agents that target antigens [44].

Alemtuzumab pharmacokinetics have been characterized in B-cell chronic lymphocytic leukemia and post stem-cell transplant patients receiving the drug for cancer chemotherapy, usually in combination with other antineoplastic drugs [43-45]. No similar data are available in the MS population and caution should be used when extrapolating existing information. On the other hand, alemtuzumab in some chemotherapy studies was given by intravenous infusion in doses and regimens similar to those utilized in the MS studies. Limited pharmacokinetic information is available from late 1990s studies in rheumatoid arthritis patients, although doses used in those studies were typically much larger than MS doses [46].

It is believed that alemtuzumab serum concentrations of $1-10 \mathrm{mcg} / \mathrm{ml}$ are associated with cellular processes that mediate lymphocyte lysis. Results of studies in bone marrow transplant patients have shown that 10 gm doses given over 5 or 10 consecutive days resulted in mean peak alemtuzumab concentrations of $2.5 \mathrm{mcg} / \mathrm{ml}$ and 6.1 $\mathrm{mcg} / \mathrm{ml}$, respectively; the drug could still be detected 11 23 days after the last dose [45]. Mould et al. [44] deter- mined that the best pharmacokinetic model to describe alemtuzumab was a two-compartment model with zero order input and non-linear Michaelis-Menten elimination strongly influenced by the covariate of the white blood cell count [44].

While the half-life of a drug varies with concentration and time in nonlinear kinetics (i.e. elimination slows with subsequent doses), the elimination of alemtuzumab after repeated doses is clearly prolonged. A half-life range of 5 - 9 days was determined in rheumatoid arthritis patients receiving 100,250 , or $400 \mathrm{mg}$ doses divided over $5-10$ days [46]. A more prolonged half-life range of $15-21$ days was measured after alemtuzumab $10 \mathrm{mg}$ given for 5 or 10 days to patients in preparation for stem-cell transplant [45]. Large interpatient variability has also been seen for the volume of distribution (approximately 0.2 $\mathrm{L} / \mathrm{kg}$ ) of alemtuzumab in B-cell chronic leukemia patients; this is likely attributable to patient status but also is caused by changes in CD52 antigen availability [44]. Since the mechanism of clearance of alemtuzumab from the body is not completely understood, dosage adjustments based on gender, age, or hepatic or renal function are not available [43]. Furthermore, the clearance of alemtuzumab has been correlated with clinical outcome by Hale et al. [47] who found that chronic lymphocytic leukemia patients who responded to treatment also had slower clearance of the drug [47].

The pharmacodynamics of alemtuzumab are primarily centered on lymphocytes that express the CD52 antigen. Interindividual variability of pharmacodynamic properties of alemtuzumab is also great since baseline white blood cell counts vary between patients and a wide range of plasma concentrations of CD52 have been determined in patients $[43,44]$. Lymphocyte depletion \& reconstitution have been investigated in the MS studies. Consistent with cancer studies, lymphocytes were rapidly depleted days after and slowly reconstituted only months after alemtuzumab treatment in the MS studies [45].

Hill-Cawthorne et al. [48] recently described lymphocyte reconstitution in 36 SPMS or PPMS patients treated with alemtuzumab between1991-1997 and followed for 384 total person-years. The mean recovery time to the lower end of the normal range was 7.1 months for B-cell and 12.7 months for total lymphocyte counts. T-cell subsets $\mathrm{CD} 4+$ and $\mathrm{CD} 8+$ counts had median recovery times of 20 and 35 months, respectively, but did not return to baseline levels in approximately $70 \%$ of patients. In the Phase II and III trials, B-cell lymphocytes reconstituted within 6 months, whereas T-cell lymphocyte recovery was slower and only approached the lower limit of normal after one year [49-51].

Finally, alemtuzumab-binding antibodies can be detected in about $30 \%$ of treated MS patients before the second course of therapy and increases to over $80 \%$ one 
month following that course. However, no association has been determined for the appearance of the antibodies and effects on alemtuzumab clinical efficacy, safety, or lymphocyte effects [49-51].

\section{Clinical Trials of Alemtuzumab}

Alemtuzumab has been studied in comparison to interferon beta-1a as an initial DMT treatment option in RRMS, and for treatment of RRMS patients who have relapsed despite previous first-line treatment. Results are available from open-label and clinical phase II and phase III trials (Table 1).

\subsection{Open Label, Non-Controlled Trials}

Cautious treatment of patients with SPMS began in 1991 when a trial was initiated to investigate alemtuzumab's effect [52]. This continued through 1999, with a total of 36 patients with SPMS being treated. Evidence of reduced annualized relapse rate (ARR) in patients $(0.7$ $0.001, \mathrm{P}<0.001)$ was seen, as well as an absence of new lesions identified on MRI; however, accumulation of disability and cerebral atrophy continued in the patients. This prompted a change in strategy to treat RRMS patients prior to onset of SPMS.

The subsequent cohort consisted of 22 RRMS patients

Table 1. Clinical trial summaries for alemtuzumab in MS.

\begin{tabular}{|c|c|c|c|c|c|c|c|c|}
\hline \multirow[b]{2}{*}{ Study \& duration } & \multirow[b]{2}{*}{ Subject Characteristics } & \multirow[b]{2}{*}{ Regimen } & \multirow[b]{2}{*}{$\mathrm{n}$} & \multicolumn{2}{|r|}{ ARR } & \multicolumn{2}{|c|}{ Mean EDSS } & \multirow[b]{2}{*}{ Comments } \\
\hline & & & & $\begin{array}{c}\text { Before } \\
\text { tx }\end{array}$ & $\begin{array}{l}\text { Following tx } \\
\text { (reduction \%) }\end{array}$ & $\begin{array}{c}\text { Before } \\
\text { tx }\end{array}$ & $\begin{array}{c}\text { Following tx } \\
(\Delta \text { EDSS })\end{array}$ & \\
\hline $\begin{array}{l}\text { Coles et al. }[52] \\
\text { Follow-up: } \\
29 \text { months }\end{array}$ & $\begin{array}{l}\text { RRMS } \\
77 \% \text { female }\end{array}$ & $\begin{array}{l}\text { Alemtuzumab } \\
20 \mathrm{mg}\end{array}$ & 22 & 2.94 & $\begin{array}{c}0.19 \\
(94 \%)\end{array}$ & 4.8 & $3.6(-1.2)$ & \\
\hline $\begin{array}{l}\text { Hirs et al. }[53] \\
\text { Follow-up: } \\
22 \text { months }\end{array}$ & $\begin{array}{l}\text { RRMS } \\
\text { Mean age: } 34 \text { years } \\
62 \% \text { female }\end{array}$ & $\begin{array}{l}\text { Alemtuzumab } \\
12-30 \mathrm{mg}\end{array}$ & 39 & 2.44 & $0.19(92 \%)$ & 4.45 & $4.09(-0.36)$ & \\
\hline $\begin{array}{l}\text { Fox et al. }[36] \\
\text { Follow-up: } \\
24 \text { months }\end{array}$ & $\begin{array}{l}\text { RRMS } \\
\text { Mean age: } 37 \text { years } \\
76 \% \text { female }\end{array}$ & $\begin{array}{l}\text { Alemtuzumab } \\
24 \mathrm{mg}\end{array}$ & 45 & 1.6 & $0.17(94 \%)$ & 2.3 & $1.92(-0.38)$ & \\
\hline $\begin{array}{l}\text { CAMMS223 [49] } \\
\text { Phase II first-line } \\
\text { therapy } \\
\text { Follow-up: } \\
36 \text { months }\end{array}$ & $\begin{array}{l}\text { Untreated RRMS } \\
\text { Mean age: } 32 \text { years } \\
64 \% \text { female }\end{array}$ & $\begin{array}{l}\text { Alemtuzumab } \\
12 \mathrm{mg} \\
\text { Alemtuzumab } \\
24 \mathrm{mg} \\
\text { IFN } \beta 1 \mathrm{a} \\
44 \mathrm{mcg}\end{array}$ & $\begin{array}{l}112 \\
110 \\
111\end{array}$ & $\begin{array}{l}\geq 2.3 \\
\geq 2.2 \\
\geq 2.2\end{array}$ & $\begin{array}{c}0.11(69 \%) \\
0.08(79 \%) \\
----\end{array}$ & $\begin{array}{l}1.9 \\
2.0 \\
1.9\end{array}$ & $\begin{array}{l}1.58(-0.32) \\
1.55(-0.45) \\
2.28(0.38)\end{array}$ & $\begin{array}{l}6 \text { month SAD: } 75 \% \text { TE in } 12 \mathrm{mg} \\
\text { group }(\mathrm{P}<0.001) ; 67 \% \text { TE in } 24 \\
\text { mg group }(\mathrm{P}<0.003) \\
\text { Median change in lesion load on } \\
\mathrm{T}_{2} \text {-weighted } \mathrm{MRI}:-17.7 \text { in } 12 \mathrm{mg} \\
\text { group and }-19.2 \text { in } 24 \mathrm{mg} \text { group vs } \\
-12.1 \text { in IFN } \beta 1 \text { a group }(\mathrm{P}=0.01)\end{array}$ \\
\hline $\begin{array}{l}\text { CAMMS223 [54] } \\
\text { five-year extension } \\
\text { Follow-up: } \\
60 \text { months }\end{array}$ & $\begin{array}{l}\text { Patients from } \\
\text { CAMMS223 }\end{array}$ & $\begin{array}{l}\text { Alemtuzumab } \\
12 \mathrm{mg} \\
\text { Alemtuzumab } \\
24 \mathrm{mg} \\
\text { IFN } \beta 1 \mathrm{a} \\
44 \mathrm{mcg}\end{array}$ & $\begin{array}{l}112 \\
110 \\
111\end{array}$ & & $\begin{array}{c}0.12(66 \%) \\
0.11(71 \%) \\
0.35\end{array}$ & $\begin{array}{l}1.19 \\
2.0 \\
1.9\end{array}$ & $\begin{array}{c}1.04(-0.15) \\
1.56(-0.44) \\
0.46\end{array}$ & $\begin{array}{l}\text { SAD from baseline to month } 60 \text { : } \\
69 \% \text { TE in } 12 \mathrm{mg}(\mathrm{P}=0.0005) \\
75 \% \text { TE in } 24 \mathrm{mg}(\mathrm{P}=0.0001)\end{array}$ \\
\hline $\begin{array}{l}\text { CARE-MS I [50] } \\
\text { Phase III } \\
\text { first-line therapy } \\
\text { Follow-up: } \\
2 \text { years }\end{array}$ & $\begin{array}{l}\text { Untreated RRMS } \\
\text { Mean age: } 33 \text { years } \\
65 \% \text { female }\end{array}$ & $\begin{array}{l}\text { Alemtuzumab } \\
12 \mathrm{mg} \\
\text { IFN } \beta 1 \mathrm{a} \\
44 \mathrm{mcg}\end{array}$ & 376 & $\begin{array}{l}1.8 \\
1.8\end{array}$ & $\begin{array}{l}0.18 \\
0.39\end{array}$ & $\begin{array}{l}2.0 \\
2.0\end{array}$ & $\begin{array}{l}1.6(-0.14) \\
1.6(-0.14)\end{array}$ & $\begin{array}{l}\text { SAD: Rates did not differ } \\
\text { between groups }(\mathrm{P}=0.22) \\
\text { MRI: gadolinium-enhancing } \\
\text { lesions: } 7 \% \text { in alemtuzumab group } \\
\text { vs } 19 \% \text { in IFN } \beta 1 \text { a group }(\mathrm{P}<0.0001) \text {; } \\
\text { new or enlarged T2-hyperintense } \\
\text { lesions: } 48 \% \text { in alemtuzumab group } \\
\text { vs } 58 \% \text { in IFN } \beta 1 \text { a group }(\mathrm{P}=0.04)\end{array}$ \\
\hline $\begin{array}{l}\text { CARE-MS II[51] } \\
\text { Phase III - previous } \\
\text { use of DMT } \\
\text { Follow-up: }\end{array}$ & $\begin{array}{l}\text { RRMS post-tx relapse } \\
\text { Mean age: } 35 \text { years } \\
67 \% \text { female } \\
\text { Mean \# of previous }\end{array}$ & $\begin{array}{l}\text { Alemtuzumab } \\
12 \mathrm{mg} \\
\text { Alemtuzumab } \\
24 \mathrm{mg}\end{array}$ & $\begin{array}{l}435 \\
161\end{array}$ & $\begin{array}{l}1.7 \\
1.6\end{array}$ & 0.26 & $\begin{array}{l}2.7 \\
2.7\end{array}$ & $\begin{array}{c}2.53(-0.17) \\
----\end{array}$ & $\begin{array}{l}\text { SAD vs IFN } \beta 1 \text { a: } 13 \% \text { in } \\
\text { alemtuzumab groups vs } 20 \% \\
\text { in IFN } \beta 1 \text { a group; } 42 \% \mathrm{RR} \text { in } \\
\text { alemtuzumab group }(\mathrm{P}=0.0084)\end{array}$ \\
\hline 2 years & MS drugs used: 1 & $\begin{array}{l}\text { IFN } \beta 1 \mathrm{a} \\
44 \mathrm{mcg}\end{array}$ & 202 & 1.5 & 0.52 & 2.7 & $2.94(0.24)$ & $\begin{array}{l}\text { MRI: New or enlarging } \\
\text { T2-hyperintense lesions: } 46 \% \text { of } \\
\text { patients in alemtuzumab group vs } \\
68 \% \text { in IFN } \beta 1 \text { a group }(\mathrm{P}<0.0001) \text {; } \\
\text { gadolinium-enhancing lesions: } 9 \% \\
\text { in alemtuzumab group vs } 23 \% \\
\text { in IFN } \beta 1 \text { a group }(\mathrm{P}<0.0001)\end{array}$ \\
\hline
\end{tabular}

Abbreviations: ARR - annualized relapse rate; DMT - disease modifying therapy; EDSS - expanded disability status scale; IFN $\beta 1$ a - interferon beta-1a; ITP immune thrombocytopenic purpura; MRI - magnetic resonance imaging; RR - risk reduction; RRMS - relapsing remitting multiple sclerosis; SAD - sustained accumulation of disability; TE - treatment effect; tx - treatment; vs - versus (compared to). 
who had previously failed treatment or had high relapse rates, indicating rapidly progressing disease and poor prognosis. Patients received $20 \mathrm{mg}$ of intravenous alemtuzumab daily for five consecutive days, with the option of a three-day re-treatment after $12-18$ months and again after 12 - 30 months. Nineteen $(86 \%)$ patients received a second course, and three $(14 \%)$ patients received a third course of alemtuzumab following disease relapses. Relapse rates were compared using ARR, and changes in expanded disability status scale (EDSS) scores were used to assess accumulation of disability. After a mean 29-month follow-up, a 94\% improvement in ARR $(\mathrm{P}<0.001)$ was seen and EDSS scores had improved by an average of 1.2 points. The difference in disability outcomes between the SPMS and RRMS patients suggested the optimal time for alemtuzumab treatment was earlier in the disease process, prior to progression to SPMS [52].

The promising results in the Coles et al. [52] RRMS trial prompted another trial of alemtuzumab in 39 patients with aggressive RRMS and a poor prognosis [53]. Thirty-two (82\%) patients were treatment-naïve and seven (18\%) had previously failed DMT. Alemtuzumab doses were not consistent for all trial subjects due to changesas new information became available. However, all subjects received five consecutive days of 12 - $30 \mathrm{mg}$ alemtuzumab and three consecutive days of $1 \mathrm{~g}$ methylprednisolone at the beginning of treatment. Retreatment occurred in $13(33 \%)$ patients an average of 17 months after the first treatment, and three $(8 \%)$ patients received a third treatment an average of 19 months later. Comparison of pre- and post-treatment ARRs demonstrated a mean difference of $2.27(\mathrm{P}<0.0001)$, representing a $92 \%$ overall reduction in ARR. The mean change in EDSS after 23 months of follow-up was 0.2 for patients with stable EDSS scores prior to treatment and 0.6 in patients with unstable baseline EDSS scores [53].

In 2012, Fox et al. [36] published results of a study conducted in 45 RRMS patients who previously received interferon beta (IFN $\beta$ ) for at least six months within two years prior to the study and had two confirmed relapses during IFN $\beta$ treatment. All patients received an initial five consecutive days of alemtuzumab therapy and a three-day retreatment 12 months later. At the 24-month follow-up, a 94\% reduction in ARR $(\mathrm{P}<0.0001)$ and a mean improvement in EDSS of $0.38(\mathrm{P}=0.0542)$ were determined for the alemtuzumab compared to prior treatment period [36].

\subsection{Active Comparator Trials}

\subsubsection{CAMMS223}

The CAMMS223 study was a randomized, blinded, phase II trial to compare the effects alemtuzumab and interferon beta 1-a on ARR and sustained accumulation of disability (SAD) in previously untreated RRMS patients. This study enrolled patients from December 2002 to July 2004. Patients assigned to receive alemtuzumab were administered either $12 \mathrm{mg}(\mathrm{n}=113)$ or $24 \mathrm{mg}(\mathrm{n}=$ 110) intravenously per day for five consecutive days during the first month of therapy, then subsequently for three consecutive days at 12 and 24 months. The interferon beta 1 -a patients $(n=111)$ were titrated up to a dose of 44 mcg subcutaneously three times a week during the study. A disease relapse was defined as the appearance of new or worsening MS symptoms accompanied by a change in the neurologic examination lasting at least 48 hours and having been preceded by at least 30 days of clinical stability. The EDSS was used to assess disability, with SAD being defined as an EDSS score increase of $\geq 1.5$ points for patients with a baseline score of 0 and $\geq 1$ for patients with a baseline score of 1 or above. SAD was recorded from the date of qualifying increase in EDSS, and confirmed by EDSS scores twice during a six-month period. Patients had a mean follow-up of 36 months [49].

Alemtuzumab ARRs compared to the interferon beta 1 -a group were significantly reduced by $69 \%$ and $79 \%$ (P $<0.001$ with a NNT of 3.1 and 3.9) in the $12 \mathrm{mg}$ and 24 mg groups, respectively. At 36 months, the ARR in the pooled alemtuzumab groups was 0.10 compared to 0.36 for the interferon beta 1-a group. Compared to interferon beta 1-a, alemtuzumab therapy was associated with reductions in risk of SAD after six months of $75 \%$ (P < $0.001)$ and $67 \%(\mathrm{P}<0.001)$ in the $12 \mathrm{mg}$ and $24 \mathrm{mg}$ groups, respectively. The number needed to treat (NNT) with alemtuzumab compared to interferon beta 1-a to avoid one patient progression to $\mathrm{SAD}$ in a 36-month study period was 5.6 in the $12 \mathrm{mg}$ and 6.0 in the $24 \mathrm{mg}$ alemtuzumab groups. The mean EDSS scores significantly improved by 0.32 and 0.45 in the alemtuzumab groups, compared to a worsening of 0.38 in the interferon beta 1-a group. Finally a reduction in the volume of lesions on $\mathrm{T}_{2}$-weighted MRI was seen in all study groups, but was significantly more marked after alemtuzumab compared to interferon beta 1-a treatment $(\mathrm{P}=0.005)$.

Two notable aspects regarding alemtuzumab dosage emerged in the CAMMS223. First, outcomes for the two alemtuzumab dosage groups were not significantly different. Second, in September 2005 during the study, alemtuzumab dosing was temporarily suspended after three subjects were diagnosed with immune thrombocytopenia (ITP), an antibody and cell mediated suppression and destruction of platelets. The suspension caused two (1\%) patients in the trial to not receive alemtuzumab therapy at month 12 and $155(75 \%)$ patients to not receive alemtuzumab at the 24-month dosing time. The study protocol was amended to include formal monitor- 
ing for ITP, and alemtuzumab was resumed. But notably, no significant differences in treatment effect on disability or safety were seen between patient subgroups who received two cycles and those who received three cycles of alemtuzumab.

Adverse events occurred in $>99 \%$ of all study participants with the most common being infusion-related reactions in all groups. Serious infusion reactions occurred in three alemtuzumab patients with one patient discontinuing the drug as a result, whereas two interferon beta 1-a patients discontinued treatment due to infusion reactions. Mild to moderate infections and thyroid dysfunction were more frequent in patients receiving alemtuzumab than those receiving interferon beta $1-a$. Infection rates were highest during the month following an infusion, but no infections were life-threatening or fatal. Thyroid dysfunction occurred up to 30 months after the last dose of study medication, with serious thyroid events occurring in three alemtuzumab-treated patients. Six alemtuzumab and 1 interferon beta 1-a patients developed ITP over a mean follow-up period of 4.5 years; the difference was not statistically significant. The overall incidence rate of ITP for all patients treated with alemtuzumab was 6.2 per 1000 person-years, with 4.2 per 1000 person-years in the $12 \mathrm{mg}$ group and 8.0 per 1000 person-years in the $24 \mathrm{mg}$ group, respectively. In comparison, the rate of ITP in the interferon beta 1 -a treated patients was 2.7 per 1000 person-years. Study dropouts occurred not only due to adverse events but also due to lack of DMT efficacy; $83 \%$ of all alemtuzumab and $59 \%$ of interferon beta $1-$ a patients completed the 36-month study.[49]

An extension to the CAMMS223 study was initiated in August 2006, four years after initial enrollment into the first study. [54] The extension study was composed of 198 of the original 334 participants and included patients from each of the three treatment (alemtuzumab $12 \mathrm{mg}$ and $24 \mathrm{mg}$ and interferon beta 1 -a $44 \mathrm{mcg}$ ) groups. Of the original study groups, 47 patients $(42 \%)$ who continued interferon beta 1 -a and 151 patients $(68 \%)$ who received alemtuzumab 36 to 48 months earlier were assessed in the extension study. Outcomes were assessed from baseline of the original trial period to 60 months. During the extension period, all patients were permitted to use other DMTs for MS including interferon beta 1-a. In 2008, patients in the alemtuzumab groups were given the option to receive additional alemtuzumab $12 \mathrm{mg}$ per day for 3 consecutive days, but the majority of patients did not receive additional alemtuzumab.

Results of the extension study showed that, compared with interferon beta 1-a, alemtuzumab decreased the risk of SAD by $69 \%(\mathrm{p}<0.0001)$ in the $12 \mathrm{mg}$ group and $75 \%$ in the $24 \mathrm{mg}$ group $(\mathrm{p}<0.0001)$ and decreased the ARR by $66 \%(\mathrm{p}<0.0001)$ in the $12 \mathrm{mg}$ group and $71 \%$ $(p<0.0001)$ in the $24 \mathrm{mg}$ group [54]. The ARR in the pooled alemtuzumab groups compared to the interferon beta 1 -a group was significantly $(\mathrm{P}<0.0001)$ lower for the baseline to the 5 -year assessment $(0.11$ versus 0.35$)$ and was lower, although not statistically significant for the 3 -year to 5 -year time period $(0.14$ versus $0.28, \mathrm{P}=$ 0.072). The mean EDSS score decreased in both alemtuzumab groups while an increased mean EDSS score was experienced in the interferon beta 1-a group [54].

Adverse effects of alemtuzumab were similar to those seen in the original study. Infections due to alemtuzumab decreased in frequency as the extension study progressed and no life-threatening or fatal infections occurred; only herpes zoster infections occurred more commonly in the alemtuzumab compared to interferon beta 1 -a patients at the end of the extension study. Similarly, autoimmune adverse effects decreased during the extension study, with thyroid autoimmunity being the most common event [54].

\subsubsection{CARE-MS I}

Results of the CARE-MS I study, a phase III trial comparing alemtuzumab to interferon beta 1 -a as first line therapy, were released in 2012 [50]. The study enrolled 563 patients with confirmed, active, and untreated RRMS who had the disease less than five years and had suffered at least two relapses in the previous two years, with the most recent relapse being within the previous year. Patients also had an EDSS score of no greater than 3. Patients were randomized in a $2: 1$ ratio to receive a $12 \mathrm{mg}$ of alemtuzumab intravenous infusion for five days at study initiation and three days at 12 months, or were titrated to interferon beta 1 -a 44 mcg administered subcutaneously three times a week. All patients also received methylprednisolone $1 \mathrm{~g}$ daily by the intravenous route for 3 consecutive days at study enrollment and at 12 months. Patients were excluded if they previously received MS DMT, including immunosuppressive, investigational, or monoclonal antibody therapy, or if they had a progressive MS disease course or other clinically significant autoimmune disorder. Because of concern for an increased herpes virus infection rate, the study protocol was amended and alemtuzumab patients received oral acyclovir $200 \mathrm{mg}$ twice daily as prophylaxis. Acyclovir was given on alemtuzumab infusion days and for the next 28 days [50].

Primary efficacy outcomes assessed were MS RR and time to SAD confirmed over a 6-month period. MS relapse and SAD were defined the same as in CAMM223. Patients who did not experience a MS relapse or suffer SAD were defined as free of clinical disease activity. Secondary study outcomes included aspects of changes in the primary efficacy outcomes, brain MRI changes including the presence of both gadolinium-enhancing lesions and new or enlarging $\mathrm{T}_{2}$-hyperintense lesions, 
and safety reflected by adverse events [50].

Alemtuzumab reduced the MS RR at 2 years when the study concluded, with $77.6 \%$ of patients who received alemtuzumab relapse-free, compared to $58.7 \%$ of interferon beta 1 -a patients $(\mathrm{P}<0.0001)$. However, there was no difference between treatment groups for SAD rates, observed in $8 \%$ of alemtuzumab compared to $11 \%$ of interferon beta 1-a patients $(P=0.22)$. Interestingly, the $\mathrm{SAD}$ rate in the interferon beta 1-a group was less than half the rate that had been determined in the CAMMS223 study. A significant difference was seen for the secondary outcome of 2-year clinically disease-free prevalence, occurring in 279 (74\%) alemtuzumab compared to 104 $(56 \%)$ interferon beta 1 -a patients $(\mathrm{P}<0.0001)$.

Mixed results were observed for the MRI radiological outcomes. There was no difference $(\mathrm{P}=0.31)$ in the median change in volume of $\mathrm{T}_{2}$-hyperintense lesions between groups, although alemtuzumab compared to interferon beta 1-a was associated with a decreased proportion of patients with new or enlarging $\mathrm{T}_{2}$-hyperintense lesions $(48 \%$ versus $58 \%, \mathrm{p}=0.04)$. Moreover, there were significantly fewer patients in the alemtuzumab group with gadolinium-enhancing lesions at 24 months ( $7 \%$ versus $19 \%, \mathrm{P}<0.0001$ ), as well as a significantly smaller median change in brain parenchymal fractions $(-0.867 \%$ alemtuzumab and $-1.488 \%$ interferon beta $1-a$, $\mathrm{P}<0.0001)$. When the clinical and MRI disease-free results were combined, the joint outcome was found in $139 / 360(39 \%)$ alemtuzumab and 46/172 (27\%) interferon beta 1-a patients, respectively $(\mathrm{P}=0.006)$ [50].

At least one adverse event occurred in $96 \%$ of patients receiving alemtuzumab and $92 \%$ of patients receiving interferon beta 1-a. As seen in the CAMMS223 study, the most frequently observed adverse events in alemtuzumab patients were infusion-related reactions (90\%) and of these, $3 \%$ were serious reactions. Infections $(67 \%$ versus $45 \%$ of patients) and thyroid dysfunction $(18 \%$ versus $6 \%$ of patients) occurred more frequently in alemtuzumab compared to interferon beta 1-a treated patients, but the occurrences were predominantly mild to moderate in severity. Acyclovir prophylaxis was not found to lessen the risk of herpetic infection in alemtuzumab patients. Three alemtuzumab patients developed ITP, of which two were successfully treated and one resolved spontaneously [50].

\subsubsection{CARE-MS II}

Nearly concurrent with CARE-MS I, the phase III CARE-MS II study was conducted in RRMS patients who had MS relapse despite treatment with first line DMT [51]. Trial design mirrored that of the CARE-MS I study, but patients admitted to the CARE-MS II study had MS no longer than 10 years, an EDSS score less than 5 , and must have suffered a MS relapse after at least 6 months of treatment with interferon beta $1-\mathrm{a}$ or glatiramer. Approximately $70 \%$ of patients had previously used a single MS medication, $23 \%$ had used two MS medications, and less than $7 \%$ had used more than two MS medications [51].

Patients were randomized in a $2: 2: 1$ ratio to receive alemtuzumab $12 \mathrm{mg}$ or $24 \mathrm{mg}$ or interferon beta 1-a 44 mcg given in the same regimen used for other studies. In December of 2008 after 14 months of subject recruitment, randomization to the alemtuzumab $24 \mathrm{mg}$ arm was terminated to facilitate more rapid recruitment into the other two groups. As such, final subject groups were composed of 436 patients in the alemtuzumab $12 \mathrm{mg}, 173$ patients in the alemtuzumab $24 \mathrm{mg}$, and 231 patients in the interferon beta 1-a groups. Follow-up for the study was 24 months, and $755(90 \%)$ of participants completed the study. Primary and secondary outcomes assessed were the same as those in the MS-CARE I study, using the RR and time to 6-month SAD as primary endpoints [51].

Results of the CARE-MS II demonstrated superiority of alemtuzumab compared to interferon beta 1-a for primary study outcomes [see Table 1]. Due to the randomization change, only the alemtuzumab $12 \mathrm{mg}$ group was included for the primary endpoint comparisons with interferon beta 1-a. Alemtuzumab reduced the ARR $49.4 \%(\mathrm{P}<0.0001)$ over that observed in the interferon beta 1 -a group, with relapses occurring in $35 \%$ of alemtuzumab and $53 \%$ of interferon beta 1 -a patients, respectively. A $42 \%(\mathrm{P}=0.0084)$ reduced risk of SAD was observed with alemtuzumab, affecting 13\% alemtuzumab versus $20 \%$ interferon beta $1-\mathrm{a}$ patients. Significant benefits associated with alemtuzumab were also found for the mean change in EDSS score during the study and the percentages of patients who were relapse-free, had sustained reduction in disability for 6 months, had new or enlarging lesions on MRI, and were clinically plus MRI disease-free. When the alemtuzumab $12 \mathrm{mg}$ and $24 \mathrm{mg}$ groups were compared for clinical outcomes, only new MRI lesion formation was improved with the larger dosage [51].

A subgroup analysis was conducted in patients with highly active RRMS ( $\geq 2$ relapses in the year prior to randomization and $\geq 1$ gadolinium enhancing lesion at baseline) who had relapsed while receiving DMT. The subgroup consisted of 101 patients $(23.7 \%)$ in the alemtuzumab $12 \mathrm{mg}$ group and 42 patients $(20.8 \%)$ in the interferon beta 1-a group. After two years, $24.2 \%$ of 101 patients treated with alemtuzumab were disease-activity free compared to $0 \%$ of 42 patients treated with interferon beta 1-a $(\mathrm{P}=0.0002) ; 35.8 \%$ of patients in the alemtuzumab subgroup had relapses compared to $60 \%$ in the interferon beta 1 -a subgroup, $7.4 \%$ had SAD compared to $17.5 \%$ in the alemtuzumab and interferon beta $1-$ a subgroups, respectively [55]. 
Adverse events occurred in $98 \%$ of alemtuzumab treated patients and $95 \%$ of patients treated with interferon beta 1-a [51]. The alemtuzumab $24 \mathrm{mg}$ group was separately included in the safety analysis and more commonly caused infusion-related adverse events, although serious infusion-related events occurred in only $3 \%$ of patients in each group. As seen in other studies, alemtuzumab at either dose compared to interferon beta 1-a was associated with a greater incidence of infections ( $78 \%$ versus $66 \%$ ), thyroid disorders $(17 \%$ versus $5 \%)$, and autoimmune thrombocytopenia (7 versus no patients); all of the adverse effects were slightly more common in the alemtuzumab $24 \mathrm{mg}$ group [51].

\section{Safety and Tolerability}

Safety issues consistently observed in studies of alemtuzumab include common infusion-related reactions, increased risk of mild to moderate infections, and autoimmunity that is primarily directed at the thyroid, but in some cases causes ITP (Table 2). Autoimmunity is thought to be the result of a combination of alemtuzumab-induced lymphopenia and increased IL-21 levels [56,57]. Lymphopenia is induced after a single dose of alemtuzumab and persists for several years after a fiveday course. Repopulation of lymphocytes leads to a change in lymphocyte proportions and altered functionality of $\mathrm{T}$ cells, resulting in highly proliferative self-reactive T cells. IL-21 was found to induce T cell proliferation and apoptosis, [56] making the combination of altered $\mathrm{T}$ cell functionality and overproduction of IL-21 a feasible cause of alemtuzumab-induced autoimmunity [56,57].

The occurrence of adverse events per person-year ranged from $7.2-8.66$ in alemtuzumab $12 \mathrm{mg}$ groups compared to 4.94 - 5.69 in interferon beta 1-a groups in the three primary studies; the incidence for alemtuzumab $12 \mathrm{mg}$ dropped to 5.67 compared to 4.49 with interferon beta $1-\mathrm{a}$ in the CAMMS223 extension study. However, the incidence of serious adverse effects was not different between treatment groups. Moreover, drug discontinuation due to adverse effects was notably decreased in the alemtuzumab $(1 \%$ - $3 \%)$ compared to interferon beta $1-a$ $(6 \%-12.1 \%)$ groups; this was a statistically significant $(\mathrm{p}<0.001)$ finding in the CAMMS223 study.

Infusion reactions due to alemtuzumab can largely be controlled using methylprednisolone, antihistamines, and antipyretics. The overall infection rate with alemtuzumab compared to interferon beta 1-a was increased by approximately $20 \%$ in DMT treatment-naïve and $10 \%$ in DMT treatment-experienced patients. Predominant infections encountered in the studies were upper and lower respiratory tract, urinary tract, and herpes viral infections. Most infections were mild-to-moderate in severity,
Table 2. Adverse events in alemtuzumab clinical trials.

\begin{tabular}{|c|c|c|}
\hline \multirow[t]{2}{*}{ Event } & \multicolumn{2}{|c|}{ Incidence (\%) } \\
\hline & Alemtuzumab & IFN $\beta 1 \mathrm{a}$ \\
\hline Infusion-associated event & $90-99$ & NA \\
\hline Headache & $43-63$ & NA \\
\hline Rash & $39-60$ & NA \\
\hline Pyrexia & $16-33$ & NA \\
\hline Nausea & $14-24$ & NA \\
\hline Urticaria & $11-27$ & NA \\
\hline Chills & $7-14$ & NA \\
\hline Infections & $67-83$ & $45-66$ \\
\hline Nasopharyngitis & $20-32$ & $13-24$ \\
\hline Urinary tract infection & $17-23$ & $4-12$ \\
\hline Herpes viral infection & 16 & $3-4$ \\
\hline URTI & $15-21$ & $12-27$ \\
\hline Autoimmune-associated events & $16-26$ & $3-6$ \\
\hline Hyperthyroidism & $7-16$ & $1-2$ \\
\hline Hypothyroidism & $5-7$ & $1-2$ \\
\hline ITP & $1-3$ & $<1$ \\
\hline \multicolumn{3}{|l|}{ Other } \\
\hline Fatigue & $13-30$ & $9-30$ \\
\hline Flu like illness & $2-8$ & $23-27$ \\
\hline Headache & $23-63$ & $18-28$ \\
\hline Rash & $12-60$ & $4-14$ \\
\hline Insomnia & $9-14$ & 15 \\
\hline Anxiety & $9-12$ & 11 \\
\hline Depression & $13-16$ & 18 \\
\hline
\end{tabular}

Abbreviations: ITP: immune thrombocytopenic purpura; URTI: upper respiratory tract infection.

although the occurrence of serious adverse events compared to interferon beta $1-\mathrm{a}$ also was increased by about $1 \%$ with alemtuzumab. Increased herpes viral infections were mostly local and were not decreased by the use of prophylactic acyclovir.

Of greatest concern are the autoimmune adverse effects of alemtuzumab. The drug-related autoimmunity most commonly results in thyroid dysfunction that occurs in $17 \%-22.7 \%$ of alemtuzumab compared to $2.8 \%-6 \%$ of interferon beta 1-a patients. The observed thyroid dysfunction included a full spectrum of effects including hyper- and hypothyroidism, thyroiditis, and goiter; almost all episodes were mild or moderate in severity and 
managed with conventional therapy. Comprehensive monitoring uncovered many of the thyroid adverse events and also provided for early detection and treatment of ITP. ITP occurred in $0.8 \%-2.8 \%$ of alemtuzumab patients but most were classified as a serious adverse event [49-51]. Alemtuzumab currently carries a black box warning for fatal cytopenias, infusion reactions and infections and is classified as pregnancy category $\mathrm{C}$ by the FDA [58].

\section{Conclusions}

MS is a lifelong illness and as such requires lifelong treatment. Current first-line DMTs for MS offer modest clinical benefit and have considerable adverse effects associated with their use. Previous parenteral therapies for treatment of MS require at least weekly administration, whereas alemtuzumab administration is necessary only five days in the first 12 months and three days in the following 12 months, with evidence of sustained clinical benefit up to 60 months and possibly beyond.

When available alemtuzumab studies are evaluated together, consistent benefit from the investigational agent compared to conventional therapy has been seen in both previously untreated RRMS patients and those who have relapsed on first-line conventional therapy. Significant decreases in the primary outcome of MS RR have been associated with alemtuzumab in each study and a reduced risk of SAD is observed in both the CAMMS223 and the CARE-MS II trials. Safety outcomes for both the $12 \mathrm{mg}$ and $24 \mathrm{mg}$ alemtuzumab doses were similar, and efficacy of the $24 \mathrm{mg}$ dose was evaluated only in the CAMMS223 trial, with no differences seen between doses for clinical or MRI efficacy outcomes.

Adverse effects associated with alemtuzumab infusions usually occur within one month of administration and can be screened for and effectively managed or treated. Nevertheless, the drug has been associated with an increased frequency of adverse effects compared to interferon beta 1-a-based therapy. Specifically, increased vigilance for infections and autoimmune diseases, including mainly thyroid dysfunction but also immune thrombocytopenia, appears to be required for alemtuzumab therapy.

Current trials have shown sustained benefit up to 60 months when alemtuzumab therapy is administered at 0 , 12, and 24 months. However, continued dosing of alemtuzumab beyond the $24^{\text {th }}$ month has not been evaluated. This is an area for continued research and will require an extended duration of study.

Alemtuzumab, marketed under the trade name Lemtrada $^{\mathrm{TM}}$, gained support from the European Medicines Agency's (EMA) Committee for Medicinal Products for Human Use (CHMP) in June 2013 [59] and was approved for the treatment of RRMS by the European Commission in September 2013 [60]. Alemtuzumab is currently under review by the US FDA for the treatment of RRMS [59].

\section{REFERENCES}

[1] R. L. Talbert, J. T. DiPiro, G. R. Matzke, L. M. Posey, B. G. Wells and G. C. Yee, "Multiple Sclerosis," In: R. L Talbert, J. T. DiPiro, G. R. Matzke, L. M. Posey, B. G. Wells and G. C. Yee (Eds.), Pharmacotherapy: A Pathophysiologic Approach, 8e.

http://nv-ezproxy.roseman.edu:2062/content.aspx?aID=7 984977

[2] J. Noseworthy, C. Lucchinetti, M. Rodriguez and B. Weinshenker, "Multiple Sclerosis," The New England Journal of Medicine, Vol. 343, No. 13, 2000, pp. 938-952. http://dx.doi.org/10.1056/NEJM200009283431307

[3] C. Polman, S. Reingold, B. Banwell, M. Clanet, J. A. Cohen, M. Filippi, K. Fujihara, E. Havrdova, M. Hutchinson, L. Kappos, F. D. Lublin, X. Montalban, P. O'Connor, M. Sandberg-Wollheim, A. J. Thompson, E. Waubant, B. Weinshenker and J. S. Wolinsky, "Diagnostic Criteria for Multiple Sclerosis: 2010 Revisions to the Mcdonald Criteria," Annals of Neurology, Vol. 69, No. 2, 2011, pp. 292-302. http://dx.doi.org/10.1002/ana.22366

[4] E. Zintzaras, C. Doxani, T. Mprotsis, C. Schmid and G. Hadjigeorgiou, "Network Analysis of Randomized Controlled Trials in Multiple Sclerosis," Clinical Therapeutics, Vol. 34, No. 4, 2012, pp. 857-869.

http://dx.doi.org/10.1016/j.clinthera.2012.02.018

[5] M. Pugliatti, S. Sotgiu and G. Rosati, "The Worldwide Prevalence of Multiple Sclerosis," Clinical Neurology and Neurosurgery, Vol. 104, No. 3, 2002, pp. 182-191. http://dx.doi.org/10.1016/S0303-8467(02)00036-7

[6] G. Rosati, "The Prevalence of Multiple Sclerosis in the World: An Update," Neurological Sciences, Vol. 22, No. 2, 2001, pp. 117-139. http://dx.doi.org/10.1007/s100720170011

[7] G. Dean, H. McLoughlin, R. Brady, A. Adelstein and J. Tallett-William, "Multiple Sclerosis among Immigrants in Greater London," British Medical Journal, Vol. 1, No. 6014, 1976, pp. 861-864. http://dx.doi.org/10.1136/bmj.1.6014.861

[8] B. Visscher, R. Detels, A. Coulson, R. Malmgren and J. Dudley, "Latitude, Migration and the Prevalence of Multiple Sclerosis," American Journal of Epidemiology, Vol. 106, No. 6, 1977, pp. 470-475.

[9] C. Gale and C. Martyn, "Migrant Studies in Multiple Sclerosis," Progress in Neurobiology, Vol. 47, No. 4-5, 1995, pp. 425-448.

[10] R. Marrie, "Environmental Risk Factors in Multiple Sclerosis Aetiology," Lancet, Vol. 3, No. 12, 2004, pp. 709718. http://dx.doi.org/10.1016/S1474-4422(04)00933-0

[11] A. Ascherio, K. Munger, E. Lenette, D. Spiegelman, M. A. Hernán, M. J. Olek, S. E. Hankinson and D. J. Hunter, "Epstein-Barr Virus Antibodies and Risk of Multiple Sclerosis: A Prospective Study," Journal of the American Medical Association, Vol. 286, No. 24, 2001, pp. 30833088. http://dx.doi.org/10.1001/jama.286.24.3083 
[12] R. Marrie and C. Wolfson, "Multiple Sclerosis and Epstein-Barr Virus," Canadian Journal of Infectious Diseases, Vol. 13, No. 2, 2002, pp. 111-118.

[13] B. Serafini, L. Muzio, B. Rosicarelli and A. Francesca, "Radioactive in Situ Hybridization for Epstein-Barr Virus-Encoded Small RNA Supports Presence of EpsteinBarr Virus in the Multiple Sclerosis Brain," Brain, Vol. 136, No. 7, 2013, p. e233. http://dx.doi.org/10.1093/brain/aws315

[14] R. Magliozzi, B. Serafini, B. Rosicarelli, B. Chiappetta, C. Veroni, R. Reynolds and F. Alosi, "B-Cell Enrichment and Epstein-Barr Virus Infection in Inflammatory Cortical Lesions in Secondary Progressive Multiple Sclerosis," Journal of Neuropathology \& Experimental Neurology, Vol. 72, No. 1, 2013, pp. 29-41. http://dx.doi.org/10.1097/NEN.0b013e31827bfc62

[15] L. Levin, K. Munger, M. Rubertone, C. A. Peck, E. T. Lennette, D. Spiegelman and A. Ascherio, "Temporal Relationship between Elevation of Epstein-Barr Virus Antibody Titers and Initial Onset of Neurological Symptoms in Multiple Sclerosis," Journal of the American Medical Association, Vol. 239, No. 20, 2005, pp. 24962500. http://dx.doi.org/10.1001/jama.293.20.2496

[16] P. Challoner, K. Smith, J. Parker, D. L. MacLeod, S. N. Coulter, T. M. Rose, E. R. Schultz, J. L. Bennett, R. L. Garber and M. Chang, "Plaque-Associated Expression of Human Herpesvirus 6 in Multiple Sclerosis," Proceedings of the National Academy of Sciences, Vol. 92, No. 16, 1995, pp. 7440-7444.

http://dx.doi.org/10.1073/pnas.92.16.7440

[17] J. Pietiläinen, J. Virtanen, L. Uotila, L. Saloned, M. Koskiniemi and M. Färkkilä, "HHV-6 Infection in Multiple Sclerosis. A Clinical and Laboratory Analysis," European Journal of Neurology, Vol. 17, No. 3, 2010, pp. 506-509. http://dx.doi.org/10.1111/j.1468-1331.2009.02718.x

[18] S. Simpson, B. Taylor, D. Dwyer, J. Taylor, L. Blizzard, A. L. Ponsonby, F. Pittas, T. Dwyer and 1. van der Mei, "Anti-HHV-6 IgG Titer Significantly Predicts Subsequent Relapse Risk in Multiple Sclerosis," Multiple Sclerosis Journal, Vol. 18, No. 6, 2012, pp. 799-806. http://dx.doi.org/10.1177/1352458511428081

[19] N. Summerday, S. Brown, D. Allington and M. Rivey, "Vitamin D and Multiple Sclerosis: Review of a Possible Association," Journal of Pharmacy Practice, Vol. 25, No. 1, 2011, pp. 75-84.

http://dx.doi.org/10.1177/0897190011421839

[20] G. Ebers, "Environmental Factors and Multiple Sclerosis," Lancet Neurology, Vol. 7, No. 3, 2008, pp. 268-277. http://dx.doi.org/10.1016/S1474-4422(08)70042-5

[21] N. Robertson, J. O'Riordan, J. Chataway, D. P. Kingsley, D. H. Miller, D. Clayton and D. A. Compston, "Offspring Recurrence Rates and Clinical Characteristics of Conjugal Multiple Sclerosis," Lancet, Vol. 349, No. 9065, 1997, pp. 1587-1590.

http://dx.doi.org/10.1016/S0140-6736(96)07317-5

[22] G. Ebers, I. Yee, A. Sadavnick, P. Duquette and the Canadian Collaborative Study Group, "Conjugal Multiple Sclerosis Population-Based Prevalence and Recurrence Risks in Offspring," Annals of Neurology, Vol. 48. No. 6,
2000, pp. 927-931.

http://dx.doi.org/10.1002/1531-8249(200012)48:6<927:: AID-ANA14>3.0.CO;2-F

[23] G. Ebers, D. Bulman, A. Sadovnick, D. W. Paty, S. Warren, W. Hader, T. J. Murray, T. P. Seland, P. Duquette, T. Grey, R. Nelson, M. Nicolle and D. Brunet, "A Population-Based Study of Multiple Sclerosis in Twins," The New England Journal of Medicine, Vol. 315, No. 26 1986, pp. 1638-1642.

http://dx.doi.org/10.1056/NEJM198612253152603

[24] A. Sadovnick, H. Armstrong, G. Rice, D. Bulman, L. Hashimoto, D. W. Paty, S. A. Hashimoto, S. Warren, W. Hader, T. J. Murray, et al., "A Population-Based Study of Multiple Sclerosis in Twins: Update," Annals of Neurology, Vol. 33, No. 3, 1993, pp. 281-285. http://dx.doi.org/10.1002/ana.410330309

[25] M. H. Barnett and J. W. Prineas, "Relapsing and Remitting Multiple Sclerosis: Pathology of the Newly Forming Lesion," Annals of Neurology, Vol. 55, No. 4, 2004, pp. 458-468. http://dx.doi.org/10.1002/ana.20016

[26] R. Gold, C. Linington and H. Lassmann, "Understanding Pathogenesis and Therapy of Multiple Sclerosis via Animal Models: 70 Years of Merits and Culprits in Experimental Autoimmune Encephalomyelitis Research," Brain, Vol. 129, No. 8, 2006, pp. 1953-1971. http://dx.doi.org/10.1093/brain/aw1075

[27] F. W. Gay, T. J. Drye, G. W. Dick and M. M. Esiri, “The Application of Multifactorial Cluster Analysis in the Staging of Plaques in Early Multiple Sclerosis. Identification and Characterization of the Primary Demyelinating Lesion," Brain, Vol. 120, No. 8, 1997, pp. 1461-1483. http://dx.doi.org/10.1093/brain/120.8.1461

[28] H. Lassmann, W. Brück and C. F. Lucchinetti, "The Immunopathology of Multiple Sclerosis: An Overview," Brain Pathology, Vol. 17, No. 2, 2007, pp. 210-218. http://dx.doi.org/10.1111/j.1750-3639.2007.00064.x

[29] C. F. Luchinetti, W. Brück, J. Parisi, B. Scheithauer, M. Rodriquez and H. Lassman, "Heterogeneity of Multiple Sclerosis Lesions: Implications for the Pathogenesis of Demyelination," Annals of Neurology, Vol. 47, No. 6, 2000, pp. 707-717. http://dx.doi.org/10.1002/1531-8249(200006)47:6<707:: AID-ANA3>3.0.CO;2-Q

[30] R. C. Selter and B. Hemmer, "Update on Immunopathogenesis and Immunotherapy in Multiple Sclerosis," Immunotargets and Therapy, Vol. 2, 2013, pp. 21-30.

http://www.dovepress.com/update-on-immunopathogenes is-and-immunotherapy-in-multiple-sclerosis-peer-reviewe d-article-ITT-recommendation 1

[31] J. W. Peterson, L. Bö, S. Mörk, A. Chang, R. M. Ransohoff and B. D. Trapp,"VCAM-1 Positive Microglia Target Oligodendrocytes at the Border of Multiple Sclerosis Lesions," Journal of Neuropathology \& Experimental Neurology, Vol. 61, No. 6, 2002, pp. 539-546.

[32] A. Minagar and J. S. Alexander, "Blood-Brain Barrier Disruption in Multiple Sclerosis," Multiple Sclerosis, Vol. 9, No. 3, 2003, pp. 540-549. http://dx.doi.org/10.1191/1352458503ms965oa

[33] D. M. Wingerchuk, C. F. Lucchinetti and J. H. Nosewor- 
thy, "Multiple Sclerosis: Current Pathophysiological Concepts," Laboratory Investigation, Vol. 81, No. 3, 2001, pp. 263-281. http://dx.doi.org/10.1038/labinvest.3780235

[34] H. Waldmann and G. Hale, "CAMPATH: From Concept to Clinic," Philosophical Transactions of the Royal Society B: Biological Sciences, Vol. 360, No. 1461, 2005, pp. 1707-1711. http://dx.doi.org/10.1098/rstb.2005.1702

[35] D. Gómez-Almagues, M. Solano-Genesta, L. Tarín-Arzaga, J. L. Herrera-Garza, O. G. Cantú-Rodríguez, C. H. Gutiérrez-Aguirre and J. C. Jaime-Pérez, "Low-Dose Rituximab and Alemtuzumab Combination Therapy for Patients with Steroid-Refractory Autoimmune Cytopenias," Blood, Vol. 116, No. 23, 2010, pp. 4783-4785.

http://dx.doi.org/10.1182/blood-2010-06-291831

[36] E. J. Fox, H. C. Sullivan, S. K. Gazda, L. Mayer, L. O'Donnell, K. Melia and S. L. Lake, "A Single-Arm, Open-Label Study of Alemtuzumab in Treatment-Refractory Patients With Multiple Sclerosis," European Journal of Neurology, Vol. 19, No. 2, 2012, pp. 307-311. http://dx.doi.org/10.1111/j.1468-1331.2011.03507.x

[37] L. Klotz, S. Meuth and H. Wiendl, "Immune Mechanisms of New Therapeutic Strategies in Multiple Sclerosis-A Focus on Alemtuzumab," Clinical Immunology, Vol. 142, No. 1, 2012, pp. 24-30. http://dx.doi.org/10.1016/j.clim.2011.04.006

[38] B. Bielekova and B. Becker, "Monoclonal Antibodies in MS: Mechanism of Action," Neurology, Vol. 74, No. S1, 2010, pp. S31-S40. http://dx.doi.org/10.1212/WNL.0b013e3181c97ed3

[39] S. Rodig, J. Abramson, G. Pinkus, S. P. Treon, D. M. Dorfman, H. Y. Dong, M. A. Shipp and J. L. Kutok, "Heterogeneous CD52 Expression among Hematologic Neoplasm: Implications for the Use of Alemtuzumab (CAMPATH-1H)," Clinical Cancer Research, Vol. 12, No. 23, 2006, pp. 7174-7179. http://dx.doi.org/10.1158/1078-0432.CCR-06-1275

[40] A. Minagar, S. Alexander, A. Sahraian and R. Zivadinov, "Alemtuzumab and Multiple Sclerosis: Therapeutic Application," Expert Opinion on Biological Therapy, Vol. 10, No. 3, 2010, pp. 421-429.

http://dx.doi.org/10.1517/14712591003586806

[41] J. L. Bennett and O. Stüve, "Update on Inflammation, Neurodegeneration, and Immunoregulation in Multiple Sclerosis: Therapeutic Implication," Clinical Neuropharmacology, Vol. 32, No. 3, 2009, pp. 121-132. http://dx.doi.org/10.1097/WNF.0b013e3181880359

[42] M. Klabusay, V. Sukova, P. Coupek, Y. Brychtova and J. Mayer, "Different Levels of CD52 Antigen Expression Evaluated by Quantitative Fluorescence Cytometry Are Detected on B-lymphocytes, CD34+ Cells and Tumor Cells of Patients With Chronic B-cell Lymphoproliferative Diseases," Cytometry, Vol. 72, No. 5, 2007, pp. 363370. http://dx.doi.org/10.1002/cyto.b.20181

[43] T. Elter, I. Molnar, J. Kuhlmann, M. Hallek and C. Wendtner, "Pharmacokinetics of Alemtuzumab and the Relevance in Clinical Practice," Leuk Lymphoma, Vol. 49, No. 12, 2008, pp. 2256-2262. http://dx.doi.org/10.1080/10428190802475303

[44] D. R. Mould, A. Baumann, J. Kuhlmann, M. J. Keating,S.
Weitman, P. Hillmen, L. R. Brettman, S. Reif and P. L. Bonate, "Population Pharmacokinetics-Pharmacodynamics of Alemtuzumab (Campath ${ }^{\mathrm{R}}$ ) in Patients With Chronic Lymphocytic Leukaemia and its Link to Treatment Response," British Journal of Clinical Pharmacology, Vol. 64, No. 3, 2007, pp. 278-291. http://dx.doi.org/10.1111/j.1365-2125.2007.02914.x

[45] P. Rebello, K. Cwynarski, M. Varughese, A. Eades, J. F. Apperley and G. Hale, "Pharmacokinetics of CAMPATH-1H in BMT Patients," Cytotherapy, Vol. 3, No. 4, 2001, pp. 261-267. http://dx.doi.org/10.1080/146532401317070899

[46] J. D. Isaacs, V. K. Manna, N. Rapson, K. J. Bulpitt, B. L. Hazleman, E. L. Matteson, E. W. St.Clair, T. J. Schnitzer and J. M. Johnston, "Campath-1H in Rheumatoid Arthritis-An Intravenous Dose-Ranging Study," British Journal of Rheumatology, Vol. 35, No. 3, 1996, pp. 131-140. http://dx.doi.org/10.1093/rheumatology/35.3.231

[47] G. Hale, P. Rebello, L. R. Brettman, C. Fegan, B. Kennedy, E. Kimby, M. Leach, J. Lundin, H. Mellstedt, P. Moreton, A. C. Rawstron, H. Waldmann, A. Osterborg and P. Hillmen, "Blood Concentrations of Alemtuzumab and Antiglobulin Responses in Patients With Chronic Lymphocytic Leukemia Following Intravenous or Subcutaneous Routes of Administration," Blood, Vol. 104, No. 4, 2004, pp. 948-955. http://dx.doi.org/10.1182/blood-2004-02-0593

[48] G. A. Hill-Cawthorne, T. Button, O. Tuohy, J. L. Jones, K. May, J. Somerfield, A. Green, G. Giovannoni, D. A. S. Compston, M. T. Fahey and A. J. Coles, "Long Term Lymphocyte Reconstitution after Alemtuzumab Treatment of Multiple Sclerosis," Journal of Neurology, Neurosurgery, and Psychiatry, Vol. 83, No. 3, 2012, pp. 298304. http://dx.doi.org/10.1136/jnnp-2011-300826

[49] A. J. Coles, D. A. Compston, K. W. Selmaj, S. L. Lake, S. Moran, D. H. Margolin, K. Norris and P. K. Tandon, "Alemtuzumab vs. Interferon Beta-1a in Early Multiple Sclerosis," The New England Journal of Medicine, Vol. 359, No. 17, 2008, pp. 1786-1801. http://dx.doi.org/10.1056/NEJMoa0802670

[50] J. A. Cohen, A. J. Coles, D. L. Arnold, C. Confavreux, E. J. Fox, H. P. Hartung, E. Havrdova, K. W. Selmaj, H. L. Weiner, E. Fisher, W. Brinar, G. Giovannoni, M. Stojanovic, B. I. Ertik, S. L. Lake, D. H. Margolin, M. A. Panzara and D. A. Compston, "Alemtuzumab Versus Interferon Beta 1a as First-Line Treatment For Patients With Relapsing-Remitting Multiple Sclerosis: A Randomized Controlled Phase 3 Trial," Lancet, Vol. 380, No. 9856, 2012, pp. 1819-1828. http://dx.doi.org/10.1016/S0140-6736(12)61769-3

[51] A. J. Coles, C. L. Twyman, D. L. Arnold, J. A. Cohen, C. Confavreux, E. J. Fox, H. P. Hartung, E. Havrdova, K. W. Selmaj, H. L. Weiner, T. Miller, E. Fisher, R. Sandbrink, S. L. Lake, D. H. Margolin, P. Oyuela, M. A. Panzara and D. A. Compston, "Alemtuzumab for Patients With Relapsing Multiple Sclerosis after Disease-Modifying Therapy: A Randomized Controlled Phase 3 Trial," Lancet, Vol. 380, No. 9856, 2012, pp. 1829-1839. http://dx.doi.org/10.1016/S0140-6736(12)61768-1

[52] A. J. Coles, A. Cox, E. Le Page, J. Jones, S. A. Trip, J. 
Deans, S. Seaman, D. H. Miller, G. Hale, H. Waldmann and D. A. Compston, "The Window of Therapeutic Opportunity in Multiple Sclerosis: Evidence From Monoclonal Antibody Therapy," Journal of Neurology, Vol. 253, No. 1, 2006, pp. 98-108. http://dx.doi.org/10.1007/s00415-005-0934-5

[53] C. Hirst, A. Pace, T. Pickersgill, R. Jones, B. N. McLean, J. P. Zajicek, N. J. Scolding and N. P. Robetrson, "Campath 1-H Treatment in Patients With Aggressive Relapsing Remitting Multiple Sclerosis," Journal of Neurology, Vol. 255, No. 2, 2008, pp. 231-238. http://dx.doi.org/10.1007/s00415-008-0696-y

[54] A. J. Coles, E. Fox, A. Vladic,S. K. Gazda, V. Brinar, K. W. Selmaj, A. Skoromets, I. Stolyarov, A. Bass, H. Sullivan, D. H. Margolin, S. L. Lake, S. Moran, J. Palmer, M. S. Smith and D. A. Compston, "Alemtuzumab More Effective Than Interferon $\beta$-1a at 5-Year Follow-Up of CAMMS223 Clinical Trial," Journal of Neurology, Vol. 78, No. 14, 2012, pp. 1069-1078. http://dx.doi.org/10.1212/WNL.0b013e31824e8ee7

[55] S. Krieger, D. Arnold, J. Cohen, A. J. Coles, C. Confavreux, E. J. Fox, H. Hartung, E. Havrdova, K. Selmaj, H. L. Weiner, T. A.Miller, C. L. Twyman, S. L. Lake, D. H. Margolin, M. A. Panzara and A. Compston, "Alemtuzumab is Efficacious in Highly-Active RRMS Patients in
CARE-MS II," 2013.

https://cmscactrims.confex.com/cmscactrims/2013/webpr ogram/Paper1191.html

[56] J. L. Jones, C. Phuah, A. L. Cox, S. A. Thompson, M. Ban, J. Shawcross, A. Walton, S. J. Sawcer, A. Compston and A. J. Coles, "IL-21 Drives Secondary Autoimmunity in Patients With Multiple Sclerosis, Following Therapeutic Lymphocyte Depletion With Alemtuzumab (Campath1H)," Journal of Clinical Investigation, Vol. 119, No. 7, 2009, pp. 2052-2061.

[57] L. Costelloe, J. Jones and A. Coles, "Secondary Autoimmune Diseases Following Alemtuzumab Therapy for Multiple Sclerosis," Expert Review of Neurotherapeutics, Vol. 12, No. 3, 2012, pp. 333-341. http://dx.doi.org/10.1586/ern.12.5

[58] Alemtuzumab, "Millennium and ILEX Partners," 2001.

[59] S. Jeffrey, "Lemtrada Gets Positive Opinion from European CHMP in MS," 2013. http://www.medscape.com/viewarticle/807066

[60] "European Commission Approves Genzyme's Multiple Sclerosis Treatment LemtradaTM (alemtuzumab)," 2013. http://online.wsj.com/article/PR-CO-20130917-900101.ht $\mathrm{ml}$ 